\title{
La documentación pedagógica como posibilidad de re-encuentro con las infancias en la formación inicial: Polifonía de miradas a tres voces
}

Datos de contacto:

Gonzalo Maldonado-Ruiz Universidad de Málaga gonzamaldo@uma.es

Isabel María Fernández García Universidad de Málaga ifergar@uma.es

Encarnación Soto Gómez Universidad de Málaga esoto@uma.es

Recibido: $26 / 03 / 2020$ Aceptado: 22/07/2020

\author{
Gonzalo MALDONADO-RUIZ \\ Isabel María FERNÁNDEZ GARCÍA \\ Encarnación SOTO GÓMEZ
}

\section{RESUMEN}

Este es el relato de una experiencia de formación donde comparten espacio las voces de dos estudiantes del Grado en Educación Infantil de la Universidad de Málaga y la de su tutora de prácticas. Desde este lugar, se conjugan para narrar en primera persona, la experiencia vivida a raíz y en relación con la documentación pedagógica. Una estrategia didáctica que no pretende "atrapar" la infancia, sino que estimula y sitúa al docente, en este caso al docente en formación, frente a la singularidad de los niños y niñas como sujetos de experiencia, y que, al mismo tiempo, nos ayuda a pensar en las posibilidades que puede tener no solo como espacio de interpretación, significación y encuentro, sino como estrategia transformadora del conocimiento práctico, singular y biográfico, del docente en la formación inicial. Así, además de entender epistemológicamente el sentido que la documentación pedagógica puede tener para la reconstrucción de la identidad profesional, en este viaje formativo nos hemos encontrado cómo fragmentos de diarios de aprendizaje, historias de niñas y niños documentadas y revisitadas por nuestra experiencia alumbran un nuevo escenario educativo que requiere nuevos modos de habitarlo como docente. Un habitar incierto y no predictivo que impacta de forma sensible, por el desconcierto al que invita "dejarse decir" por las infancias.

PALABRAS CLAVE: Documentación Pedagógica; Conocimiento práctico; Formación Inicial; Practicum Educación Infantil; Infancias. 


\title{
Pedagogical documentation as a possibility of re-encounter with children in pre-service teachers training: Three-voice polyphony
}

\begin{abstract}
This is the story of an educational experience where the voices of two students from the Degree in Early Childhood Education at the University of Málaga and that of their apprenticeship tutor share space. From this place, they come together to narrate in first person, the experience lived as a result and in relation to pedagogical documentation. A didactic strategy that does not intend to "catch" childhood, but rather stimulates and positions the teacher, in this case the pre-service teacher, facing the uniqueness of children as subjects of experience, and which, at the same time, helps us to think about the possibilities that it can have not only as a space for interpretation, meaning and encounter, but as a transforming strategy of teacher's in initial training practical, singular and biographical knowledge. Thus, in addition to epistemologically understanding the meaning that pedagogical documentation can have for the reconstruction of professional identity, in this formative journey we have found how fragments of learning journals, children stories documented and revisited by our experience illuminate a new educational setting that requires new ways of living as a teacher. An uncertain and non-predictive way of inhabiting that impacts in a sensitive way due to the confusion caused by "letting oneself be told" by childhoods.
\end{abstract}

KEYWORDS: Pedagogical Documentation; Practical knowledge; Initial Training; Practicum; Early Childhood Education; Childhoods.

\section{Primeros acordes... a modo de introducción}

Una canción es algo más que una composición que decodificamos desde nuestro sentido del oído; es una experiencia que nos remueve y no nos deja impasibles. De la misma manera, una propuesta pedagógica es (o debería ser) una experiencia que se enclava en las biografias de las y los estudiantes para abrir la oportunidad a la metamorfosis (Pérez Gómez, 2017). Es desde este simil del que partimos para narrar una propuesta educativa en la formación inicial del profesorado de educación infantil como una experiencia sonora en la que confluyen tres voces diferenciadas: dos estudiantes que la vivieron y la profesora universitaria que la diseña y desarrolla en un contexto escolar privilegiado: el Ceip Nuestra Señora de Gracia (Málaga), un espacio amable y acogedor de las múltiples propuestas de relación que mutuamente nos ofrecemos. Así es, como en el tercer curso del Grado en Educación 
Infantil, a punto de comenzar el segundo periodo de prácticas e impacientes por "de-mostrar" las cualidades profesionales, la tutora académica desdibuja esta inercia con el reto de documentar pedagógicamente lo que ocurra en las aulas.

El eco generado por los relatos de estas voces y vivencias singulares, nos animan a compartir, y quizás sugerir, las posibilidades educativas que la documentación pedagógica ha representado para nuestra formación inicial en educación infantil. Una oportunidad para analizar nuestra manera de vivir y entender la profesión docente y sobre todo nuestra imagen de las infancias.

\section{El seísmo de la sutileza. Repensando la formación inicial de las maestras y los maestros}

En el contexto actual, el docente ha de convivir con un alto nivel de ambigüedad e incertidumbre para responder a los incesantes demandas y retos sociales e institucionales. Estos problemas prácticos plantean dilemas para los que, en la mayor parte de las ocasiones, no existen soluciones claras. Sin embargo, en la formación inicial del profesorado sigue existiendo un fuerte sesgo academicista que consolida la separación endémica de la teoría y la práctica y por tanto, no favorece la formación del pensamiento práctico. Estimula, sobre todo, procesos estériles de asimilación teórica que afectan superficialmente las teorias proclamadas y no tanto a sus teorias en uso, es decir, el conocimiento y las estrategias que ponen en acción (conocimiento práctico) en el escenario del aula (Zeichner, 2010; Pérez Gómez, 2010; Darling-Hammond \& Oakes, 2019; Soto Gómez, Serván Núñez, Trapero \& Pérez Gómez, 2019).

Cualquier acción que el estudiante desarrolla parte de un conocimiento cuajado de patrones, hábitos y creencias pedagógicas empíricas y acríticas acumuladas a lo largo de su dilatada experiencia escolar (Pérez Gómez, 2010). Un carácter complejo, emergente y holístico que abre la puerta al mundo de las emociones y las intuiciones de forma implícita y automática (Tardif, 2004; Van Manen, 1995; Greeno, Collins \& Resnick, 1996; Korthagen, 2010; Lampert, 2010; Immordino-Yang, 2011). ¿Cómo ayudar a conocer el microcosmos implícito de conocimiento, a veces contradictorio, de sus teorías declaradas (Argyris, 1993) para explicar la orientación de su conducta?

Como tutora académica, intento transcender el marco habitual de concebir la formación como un proceso que solo incorpora de forma cómoda, nuevas ideas conscientes e informadas en el conocimiento más declarativo que práctico de mis estudiantes (Pérez Gómez, Soto Gómez \& Serván Núñez, 2015). Un principio pedagógico básico que vertebra mi enseñanza es proponer estrategias de reflexión y de acción que les ayuden a reconstruir no solo los 
conocimientos, sino también las actitudes, las emociones, los hábitos y las creencias más subterráneas (Lucas \& Claxton, 2013). Un proceso que lejos de ser confortable, provoca problemas de convivencia con sus creencias y disposiciones más arraigadas. Aquellas que derivan de una biografia poco lúdica, repleta de fichas, libros de texto, órdenes, filas, obediencia y con la imagen de un profesional protagonista de la escena y poseedor de todo el saber frente a un niño o niña que todo lo debe aprender en silencio y bajo coacción (Hoyuelos, 2013a). Desde este punto de vista, la documentación pedagógica puede ayudar no solo a descubrir una infancia singular y diversa, como sujetos de experiencia, sino a descubrir-nos en relación con ella. Una forma propia de ser docente que vive el documentar como un pilar fundamental de la escuela activa que valora, respeta y confía en una infancia con un potencial ilimitado.

\section{¿Qué es la documentación pedagógica? Ladrillo a ladrillo... una manera de vivenciarla}

Para algunas autoras y autores, la documentación pedagógica se define como el "proceso sistemático de mirar y escuchar a las niñas y niños y registrar su comportamiento" (Wylie \& Fenning, 2012, p. 39). Sin embargo, además de "hacer visible su actividad nos permite reflexionar sobre ella, mejorar el trabajo de cada día y reflexionar sobre ello" (Bonàs, citada en en Red Territorial de Educación Infantil de Cataluña, 2012, p. 16). Lejos de una interpretación instrumental, se puede afirmar que documentar tiene una posición ética y política que invita a "abrirse a otros pensamientos que abrazan la singularidad, multiplicidad, el conocimiento local, las construcciones sociales, la emoción, la ambivalencia y la complejidad" (Dahlberg \& Moss, 2010, p. 112). Esta complejidad se ve reflejada en la oportunidad para poner en cuestión nuestra identidad docente y redescubrir la noción de "infancia" que, como argumenta Hoyuelos (2013b), es la primera piedra de todo nuestro trabajo. Esta imagen se va revelando gracias a la interpretación intersubjetiva de los procesos documentados. Interpretaciones que, como Curtis \& Carter (2012) explican, nos permiten analizar y contrastar las influencias, incluso de experiencias pasadas, que entran en juego para favorecer el tránsito de lo observado a la construcción de una teoría propia y abierta (Rinaldi, 1998). Y es precisamente en este movimiento de búsqueda permanente en el que se pueden desarrollar las competencias profesionales, aquellas que "orientan la interpretación, la toma de decisiones y la actuación" (Pérez Gómez, 2017, p. 95).

Sin perder de vista el controvertido debate sobre el término competencias, entendemos éstas como, cualidades humanas fundamentales, donde las emociones, valores, actitudes, conocimiento y habilidades han de concursar 
como sistemas complejos y armónicos de reflexión y acción (Pérez Gómez, 2012).

En sintesis, documentar supone investigar cualitativamente con las potencialidades de la infancia haciendo emerger nuestra propia "teoría" (Korthagen, 2008). Una investigación que "va más allá de la tentación del embeleso hacia los niños, para así intentar comprenderles desde un acercamiento verdadero" (Cabanellas, 2005, p. 196). Porque, al fin y al cabo, la documentación supone una oportunidad para resquebrajarse al visibilizar también los pensamientos de las maestras y maestros que documentan (Wien, Guyevskey \& Berdoussis, 2011), algo que en un primer momento suele provocar desconcierto e inquietud en las y los estudiantes de docente. En palabras de Davoli (2011):

Para documentar hay que observar y observar quiere decir, ante todo, conocer. Pero no se trata de un conocimiento abstracto; se trata de una emoción del conocimiento que contiene toda nuestra subjetividad, nuestras expectativas -lo que esperamos que pase-, nuestras hipótesis y nuestras teorias de referencia, en la cual nosotros también somos contenidos (p. 15).

\section{Documentación pedagógica y pensamiento práctico, un encuentro... ¿inesperado?}

Para comprender las posibilidades que la documentación pedagógica tiene en la formación inicial de docentes, se hace necesario definir y describir aquellos principios del proceso documentador que pueden, en nuestra opinión y desde nuestra experiencia, estimular momentos de encuentro y contraste con el conocimiento práctico de los estudiantes en formación. Momentos que a su vez ayudan a entender también, el sentido y el proceso metodológico de nuestra experiencia:

- Una actitud de extrañamiento. Esta disposición estética es, como denomina Hoyuelos (2011), una actitud de investigación clave para poder comenzar a recoger historias de aprendizaje. Consiste en hacer de lo familiar algo extraño (Mannay, 2017) para poder "dejarnos decir" por la cotidianidad estimulando la "suspensión" de aquellas teorias proclamadas (Argyris, 1982) que normalmente tienen peso en los análisis educativos de las maestras y maestros en formación y abriendo la puerta a la curiosidad y el deseo de aprender.

- Una disposición corporal proxémica. Que hace referencia a las relaciones, miradas y disposiciones corporales entre los participantes (Hoyuelos \& Riera, 2015). La documentación pedagógica demanda del docente una postura, una manera de estar presente en lo que acontece, que contrasta generalmente, con la disposición habitual y automática de las y los 
estudiantes. Agacharse y ponerse al nivel de las niñas y niños es un movimiento que incorpora una dimensión ética de reconocimiento y acogida del otro.

- El asombro. La disposición antes mencionada permite conectarse emocionalmente de otra manera con lo que ocurre en las aulas, ya que la sorpresa se convierte en un modo de encuentro con las historias singulares de las infancias y con nuestra propia experiencia. "La plataforma de acción de la sorpresa es la desconexión, [...] en unos segundos todo se para, y en esa parada sucede un punto de inflexión [...], un antes y un después en nuestra vida" (Aguado Romo, 2015, p. 329). Cuando algo nos asombra, es precisamente porque "no lo esperábamos" y esta "novedad" hace visible la imagen de infancia que tenemos, y que como sugiere Schön, (1992), "conduce a una reflexión dentro de una acción-presente" (p. 38).

- La interpretación de las historias. Incorpora la reflexión sobre la acción (Schön, 1998) o teorización de la práctica Hagger \& Hazel (2006). Es decir, un proceso que implica tres momentos clave: el primero, al volver a visitar las evidencias recogidas pero sin el ritmo vertiginoso que caracteriza a la práctica. Una manera de estimular la reflexión pausada del docente sobre su propia forma de actuar y de iluminar las teorias implicitas no conscientes (Pozo, 2014). Un segundo momento, de contraste intersubjetivo donde ponemos a dialogar las evidencias seleccionadas con otros profesionales y otras prácticas, a la luz de las experiencias educativas más relevantes y de los resultados de la investigación educativa más consistentes (Pérez Gómez et al., 2015). Y un tercer momento, al tener que comunicar las interpretaciones a una comunidad más amplia, desde un lenguaje orgánico que, a través de la metáfora, entre otros recursos, permite conectar elementos de la complejidad de la práctica (Morin, 2001) que de otro modo formarian "compartimentos estancos".

- La posibilidad de acción educativa. La documentación pedagógica acompaña una manera de entender la enseñanza y el rol docente. Esto supone una oportunidad para "experimentar la teoria" y cerrar el "ciclo" de desarrollo del proceso de pensamiento práctico, un proceso que va más allá de la reflexión sobre la acción, ya que requiere "convertir las nuevas teorias personales en modos concretos, sostenibles y ágiles de interpretación y actuación” (Pérez Gómez et al., 2015).

Con este marco epistémico de comprensión, la documentación pedagógica se convertía en el eje estructural del diseño previsto para el practicum II denominado "construyendo historias de vida y aprendizaje". Una propuesta donde la escritura reflexiva, las imágenes y el diálogo compartido entre el grupo de prácticos/as y la tutoría tanto universitaria como escolar, iban trenzando el diario de prácticas, los seminarios de encuentro y los portafolios narrativos y visuales. Un espacio de encuentro para re-escribir-se a sí mismo/a, en reflexión constante entorno a lo documentado tanto de modo 
presencial como virtual, donde cada cual compartiese con mimo y cuidado, aquellas imágenes, narrativas, diálogos, etc. que habían captado la atención por alguna razón especial y que, como en pause, permanecía a la espera del encuentro con las voces e interpretaciones de los/as compañeras de grupo. Las historias cotidianas y espontáneas que las niñas y los niños de los centros de prácticas deslizan ante nuestra mirada, son historias que invitan a repensarnos y a reinventarnos como docentes.

Esta propuesta invitaba a entender la infancia como vivencia multiinterpretada en sus recorridos, no encerrada en una única verdad; lo cual complementaban las constantes retroalimentaciones que complejizaban la mirada de las/los estudiantes hacia nuevas preguntas e interpretaciones, "miradas calidoscópicas sobre una misma realidad que a cada movimiento nos recuerda que es incierta" (Red Territorial de Educación Infantil de Cataluña, 2012, p.17). Este era, también, el sentido de los seminarios que tuvimos a lo largo del Practicum II: vivir un proceso intersubjetivo de construcción y deconstrucción de significados. Cuyos procesos y vivencias compartian públicamente en la Facultad a través de paneles de documentación donde narrasen estas escenas, centrando su atención en profundizar en aquello que las historias de aprendizaje seleccionadas les daban a pensar y a pensar-se como maestra y maestro. Un proceso que necesariamente incorpora una evaluación, autoevaluación y coevaluación continua, donde el docente en formación, a la luz de las evidencias y reflexiones de aprendizaje seleccionadas en su portafolios, dialoga y fundamenta con la tutora académica la reflexión final de sus aprendizajes.

\section{Resonancias de una propuesta de-formativa: armonía de dos voces estudiantes}

\section{Reconocer "la mirada que mira"}

Comprender la documentación pedagógica como "oportunidad para resquebrajarse", desde un sentido educativo, nos lleva a pensar que todo quebrar-se encuentra su inicio en algo que nos impacta. Simbólicamente, la vivencia de documentar nos provoca el sentir la movilización de nuestro propio "ser pedagógico" (Van Manen, 1998). Durante nuestro periodo de formación inicial, con frecuencia entramos en contacto con verbos sonoros como "explicar, enseñar, contar..."; quedando anquilosados en "una educación basada en la palabrería de la palabra" (Hoyuelos, 2013b, p. 172).

En el practicum anterior, nuestra atención se centraba en la maestra o en "proponer actividades" repletas de discursos que habiamos ido incorporando a nuestro catálogo de teorías proclamadas (Argyris, 1982): "autonomía, creatividad, respeto...". Sin embargo, resultaban ser palabras pervertidas en 
una retórica que nos desviaba de la pregunta pedagógica en primera persona (Contreras, 2010): ¿Quién, como adulto, me dispongo a ser para las infancias?

Poco a poco, a través de documentar y de las intensas sesiones de tutorias compartidas en las que, a través de preguntas abiertas y de textos relacionados con nuestras inquietudes e incertidumbres, ibamos descubriendo que, en realidad, nuestra imagen de infancia habia estado vinculada a "lo que no son o no saben en relación a la fabulosa sabiduría del adulto" (Malaguzzi, 1993, p. 18) como así refleja algunas evidencia de nuestro diario iniciales de práctica donde dudábamos, con perplejidad, sobre las capacidades de las niñas y niños:

Por otro lado, me sigue llamando la atención el nivel de deducción, reflexión y capacidad resolutiva que este grupo [de niñas y niños] presenta y no sé muy bien si es que, en la era de la información, los niños y niñas en general son asi o es que esta metodología promueve que se desarrollen estas capacidades. [Diario Gonzalo | 10/02/2014]

\section{La mirada quebrada}

Al "contemplar con sosiego" a las infancias, pudimos ir transitando desde aquel saber institucionalizado (el conocimiento declarativo desligado de la cotidianidad") a un saber de nuestra experiencia, un saber tejido de relaciones, reflexiones y contrastes. Tras la experiencia vivida, no podíamos seguir concibiendo la infancia como mera sucesión de etapas previsibles, sino que necesitábamos hacernos la pregunta viva "¿qué estamos dejando de mirar cuando sólo vemos lo que estandarizadamente ha de verse?”. Nuestra inquietud ya había dado un salto desde "qué se dice sobre la infancia" hacia "qué nos dice nuestra relación concreta con las infancias" y de éstas en relación con el mundo (Dahlberg, Moss \& Pence, 2005).

Quizá es así como pudimos vivirlo y lo vivimos; como ese desprenderse de la necesidad de encontrar respuestas academicistas a las incertidumbres que la cultura infantil nos despierta: "Laberinto del oído. Lo que dices se desdice" (Paz, 1990). Esa detención de la mente de la que habla Zambrano (1989) que es una detención contemplante, receptiva de los murmullos de lo inaudito que brota a través de la existencia de la infancia. Una detención que supone un "esfuerzo consciente" de pensar-nos.

Precisamente son esos murmullos antes mencionados los que queremos rescatar aquí en forma de historias que, si bien no son ni mucho menos las únicas que tuvieron relevancia en esa experiencia pedagógica, sí nos sirven para reflejar el impacto que esta experiencia tuvo en nuestro conocimiento práctico (Pérez Gómez, 2012, 2017) 


\section{El desafine que da sentido a la melodia. Una historia que tiene ecos en la identidad docente de Autor/a}

En mi caso, llegué al Grado de Educación Infantil después de haber vivido una trayectoria como "estudiante de sobresaliente" que había aprendido a no mostrarse mucho. Además, mi experiencia como animador sociocultural, dio luz a un personaje atravesado por la necesidad de contagiar alegria, que fácilmente transferí a la identidad que como docente empecé a construir en el Grado. Una identidad ajena a la idea de documentación pedagógica como un pensar-se y un mostrar-se más allá de "ser espectador" (Sparrman \& Lindgren, 2010). Se constituía así una posibilidad para un salto que me resultaba, a priori, demasiado arriesgado.

Era un riesgo porque este proceso implicaba dejarme cuestionar. Y claro, cuestionar-se es una acción que para un estudiante con éxito académico pasaba por asumir la vulnerabilidad de mi "propio rol, junto con las dudas, errores y curiosidades" (Altimir, 2010, p. 19). Este giro, que al inicio de la propuesta pedagógica de la tutora era sólo un pretexto, tomó fuerza de la mano de Ángel (3 años), quién me llevó a ver qué era lo que me frenaba para evolucionar como maestro.

Una mañana, mientras él jugaba en un espacio del aula con disfraces, pude ver cómo tomaba un vestido de color rosa. Se puso frente al espejo y con muchísima destreza, pero también gran delicadeza, se lo puso y comenzó a caminar por la clase. Dos compañeras se acercaron a preguntarle entre risas:

- Rosario: ¿Qué haces con un traje de princesa? Las princesas son para niñas.

- Ángel: No es un traje de princesa, a mi me gusta.

- Daniela: Pero es rosa. [Ambas se marchan]

Ángel siguió bastante tiempo vestido de rosa caminando hasta que, cuando él lo decidió, volvió al espacio con los disfraces y se desvistió.

Este momento me resultó muy impactante porque, con pocas acciones y sin grandes alardes, Ángel me puso en jaque. No sabria describir la emoción que documentar esta pequeña historia me produjo en ese momento, pero lo que sí recuerdo es que no era cómoda. No sabía cómo interpretar el sentido que la vivencia de ponerse un vestido rosa estaba teniendo para mí.

¿Quería ser princesa? ¿Quería ser mamá? ¿Jugaba con su sexualidad? Estas eran algunas de las preguntas que aparecían en un análisis incipiente de la escena. Sin embargo, gracias a largas conversaciones con mi tutora académica, me di cuenta de que no podía (ni debía) transformar las narrativas en proposiciones comprobables (Bruner, 1997). Dicho de otra forma, descubrí que documentar no buscaba ofrecer diagnósticos o resolver incógnitas sobre los porqués de una determinada conducta, ni siguiera busca interpretaciones generalizables, sino que esos momentos concretos abrian la oportunidad a 
una auto-indagación. Un viaje en primera persona donde "lo nuevo está en lo que nos pasa, por eso lo asombroso es que pase algo inimaginable o contradictorio" (Vilanova Buendia, 2014, p. 321). De esta manera dejó de importarme la razón que había detrás de la selección de ese traje:

Probablemente, en otro tipo de entorno, este niño no hubiese llegado ni a coger ese vestido porque se le habría explicado que no era para él, o si lo hubiese podido hacer, se hubiese resaltado ese momento como "una posible muestra de orientación sexual" u otras cuarenta estupideces más. Esta imagen representa el derecho de cada uno a desenvolverse como lo quiera hacer, sin que eso tenga que significar una definición de la propia personalidad. [Diario Gonzalo| 13/03/2015]

Así, gracias a Ángel puedo decir que la infancia que conocemos es transgresora porque rompe con lo que, como figuras adultas, creemos que es "lo normal". El encuentro con momentos de esta naturaleza revolucionaria nos permite recoger narrativas que suponen "contradiscursos" (Dahlberg et al., 2005) sociales.

Cuando tuvimos que seleccionar una historia documentada para la elaboración de los pósters finales, yo tenía muy claro que la imagen del traje debería estar presente para el debate en la comunidad universitaria. Aun sabiendo que para mi esa fotografía era crucial, a la hora de escribir sobre lo que ella me despertaba, no fui capaz de evidenciar lo que hoy sí tiene ya palabras para mí.

Ángel, con su vestido rosa, no sólo se me hacia importante porque abriera la posibilidad a plantearnos las infancias como una cultura subversiva. Yo me encontré con el niño que un día fui gracias a él. Cuando yo era pequeño, también me disfrazaba en casa con los trajes de mi padre y con los de mi madre. Esa acción cotidiana era un reflejo más de una manera diferente de vivir mi masculinidad que, a raíz de mi experiencia, no era acogida con facilidad en la sociedad. Desde ese lugar, el relato de Ángel cobraba aún más sentido en mi experiencia docente porque, en primer lugar hacía "visible" una vivencia lúdica que, desde mi biografia, sabía que requería ser reconocida y pensada. Y, además, ese vestido rosa me reconciliaba con mi propia identidad y me empujaba a llevarla conmigo dentro de la escuela, asumiendo que "ser docente es siempre una historia personal" (Contreras, 2010, p. 257). Ya no era necesario "construir un personaje" que guiara mi acción profesional; estar presente desde lo que soy se volvía una asunción política crucial en mi manera de habitar la escuela. Esta transformación me hace pensar ahora también en la posibilidad que nos ofrece la documentación pedagógica para pensar radicalmente nuestro lugar como maestras y maestros desarrollando nuestro pensamiento práctico (Pérez Gómez, 2012, 2017).

Así, una acción que en un inicio, desafinaba con los acuerdos tácitos que la sociedad traslada a la escuela, ahora daba sentido, relevancia y armonía a la melodía. 


\section{Entre-voces. Disponerse a la resonancia. Una historia que tiene ecos en la identidad docente de Autor/a.}

- "iMira Teo, sale mi voz!", exclama Dalía a través de un tubo de cartón.

- Teo tapa el hueco. "Ya no te escucho".

- Dalia, responde: “Porque si pones la mano, mi voz se queda dentro!”.

A propósito de voces... ¿En qué momento una deja de escuchar aquellas que la habitan?

Comencé el grado de Educación Infantil portando voces desatendidas en el plano del inconsciente, las cuales expresaban qué conocimiento práctico docente (Pérez Gómez, 2012) había ido gestando en el transcurso de mi experiencia escolar: un orden pre-decible para cada acontecer del mundo.

Voces que se trasladaban al presente y hablaban automáticamente por mí, cancelando la posibilidad de un pensar pedagógico en presencia y conectado a cada situación irrepetible en el aula.

En mi caso, puedo ir haciéndome consciente del ruido de estas voces cuando, a partir de observar mis paneles de documentación pedagógica en la exposición pública en la Facultad, me invade una sensación progresiva que en su momento no supe apalabrar, pero que ahora llamaría "grito ahogado". Sin ser consciente, había ido clasificando las historias de aprendizaje de las niñas y los niños en asignaturas escolares (plástica, música...) y, en lugar de pensar(me) junto con los relatos, imponía sobre sus tramas un único recorrido de pensamiento, lanzándoles una soga interpretativa que asfixiaba cualquier interlocución sensible de la cual salir trans-formada. ¿Necesitaba darle una especie de "entidad academicista" a una "historia mínima" que revelaba mi dificultad para relacionarme con la complejidad de los sucesos sutiles?

Es entonces cuando, en diálogo con la tutora, pudimos ir viviendo en piel propia cómo la documentación pedagógica nos desvelaba qué imágenes de infancia, docente y aprendizaje nos anidan, volviéndolas pensables (Dahlberg et al., 2005) y disponiéndonos hacia un estar-investigativo en el oficio. De este modo, pude advertir cómo "a-signaturizaba" automáticamente las escenas de aprendizaje, d(n)ominándolas, y perdiendo de vista cualquier signo de vida. En lugar de adentrarme en sus tramas, me las tramaba inconscientemente para salir ilesa de la extrañeza que le provocaba a mi adultez el modo de existencia de las infancias. Se trataba de historias que yo exponía, pero en las que no me ex-ponía como maestra... no ponía en juego el pensar. Es esto lo que me sucedió con Dalía y Teo, de cuatro años, a quienes capturé su relato de pensamiento en la categoría de "ciencias naturales".

¿Qué escucho cuando escucho lo que escucho? Creía pasarme el día a la escucha de las narrativas de aprendizaje de las niñas y los niños, pero... ¿Era realmente capaz de escuchar algo que no fuese mi construcción academicista del mundo? Todo ello fertilizaba en mí una incomodidad traducida en una 
"agitación formativa" (Caparrós \& Sierra, 2019) allí donde siempre había estado cómodamente asentada, en inercias que dictaban a mi escucha aquello que podía ser escuchado.

Así las cosas, esta inquietud que se instaló en mi ser docente en formación inicial, me exigía un desplazamiento existencial hacia no sabía dónde. De repente, todo está por escuchar... en un re-visitar que visita zonas inesperadas de una escena que, aun siendo la misma, permanece cambiante. Porque lo que muta es la relación de pensamiento que cada quien tiende con las historias (Contreras, 2010).

Y es precisamente la escena co-creada por esta niña y este niño la que me invita a "poner imagen" a lo que también sucede formativamente en mí misma como un tránsito desde la codificación de las historias, hacia la sensación de inacabamiento y expectación que surge cuando nos disponemos a la escucha de los murmullos dispersos del relato, a sus cien lenguajes (Malaguzzi, 1993). Porque Dalía y Teo se exponen al fenómeno de la voz como un acontecimiento con el que entrar en relación... como quien dialoga con lo intangible, con lo que escapa a la categoría.

Dalía y Teo conversando al filo del lenguaje, allí donde la palabra se convierte en un misterio vibrante. Este gesto "deformante" de la palabra pone ante mí el sentido encarnado de la "deconstrucción", donde ambos llevan el lenguaje a su esencia sonora. Un lenguaje construido como "símbolo", pero que nace de un retorcimiento originario: lo sonoro, lo anterior a toda forma. Este gesto "deconstructivo" de la infancia nos retorna a lo sustancial. ¿Acaso las historias de aprendizaje documentadas nos invitan a pensar con "eso" que nunca acaba de tener una forma exacta?

Asimismo, Dalía y Teo se vinculan con sus voces "ritualmente". Proyectan su sonoridad y esperan a que la voz estalle en el aire para volver a hilarla desde sus gargantas. Sin embargo, su persistencia placentera me hace pensar en que esa repetición no llega a convertirse en "rutina" mecánica, porque parecen vivirla desde un estado vivificante en el que estudian apasionados la repercusión que sus voces inventan: ¿cuáles son las voces de mi voz? Es por ello que esta escena de infancia podría resultar peligrosa para aquella idea hegemónica escolar de "progreso" donde niñas y niños tienen que ir pasando por una serie de secuencias en las que lo que prima es la linealidad propedéutica, quedando anulada la posibilidad de expandirse con y en una misma experiencia que, en realidad, es siempre otra, trayente de novedad.

Dalía y Teo ponen en el mundo otra forma de relación con las cosas. En esencia, sin "cosificarlas", sin exigirles ser "misteriosas"... sino adentrándose sin más en su misterio,. Es así que el tubo de cartón que estudian se les ofrece como prolongación de sus propias gargantas y les asiste en el nacimiento de la voz. Tubo que más que un objeto a usar, es una alteridad material con la que entramar sentidos e incógnitas. No sólo el tubo es atravesado por sus voces... también ellos son atravesados por los efectos que 
el tubo les devuelve.

Y así concurre la escena de Dalía y Teo, cometiendo ambos un extrañamiento compartido a la par que la extrañeza les acomete... ¿Y no es este, de algún modo, el sentido primigenio de lo educativo, esa extrañeza fundante donde lo real no se da por hecho, sino que una "se hace" junto con la realidad que va deviniendo? Es esto lo que va quedando como poso en mi formación docente... Un volver a percibir las "entre-voces" del mundo y sentirme entre los murmullos de lo inaudito de la niñez, esa polifonía que impide que mi voz lo ocupe todo. Documentar, entonces, como una invitación a resonar con las infancias en una lengua sutil, gestual, escuchante... Una lengua que es siempre infinitas lenguas.

\section{A modo de conclusión. Poniendo puntos suspensivos a la sinfonía...}

Como hemos venido narrando, en nuestra experiencia como estudiantes, nuestra mirada se fue despegando del discurso instituido para recorrer los bordes de lo que aún no habíamos pensado, reconociendo sólo así la existencia real de "la cultura de las infancias", acercándonos a "cómo los niños piensan, desean, hacen teorias o nos introducen en sus caminos emocionales" (Hoyuelos, 2013a, p. 131). Estas historias rescatadas son ejemplo de cómo todo aquello que las infancias protagonizaban en el aula y que no "merecía" nuestra atención pasaba a volverse un esfuerzo consciente constante por investigar en nuestra propia práctica y, por tanto, buscar el desarrollo de nuestras competencias profesionales. Este giro, además, tenía resonancia en los textos reflexivos que íbamos construyendo en nuestros portafolios:

[...] De ese punto he pasado a este otro en el que estoy ahora, que no es otro que el dar relevancia a esos momentos que en la escuela convencional quedan olvidados [...]. Una muestra muy clara de ello es que no existe ninguna foto ni evidencia en todo el pasado practicum que fuese tomada en el recreo. [Portafolios Gonzalo | 16/04/2015]

[...] Esa sensación de presencia, de existencia... que nos aporta la fotografía que nos documenta. Y esa sensación de que eres atendido por otros, mirado, apreciado... Grandes detalles que nos ayudan a conectar. [Diario Isabel | 01/03/2016]

Esto, además, nos ayudaba a vivir una relación diferente con lo que conocemos por teoría, porque ahora ésta emergía y se tejía con las incertidumbres de la experiencia.

Desde el quiebre, las fracturas fueron más allá de lo compacto, dejando entrar en sí aquello que no tenía pre-visto. Es así como hemos podido reconceptualizar lo que entendiamos por "infancia" para dejar atrás definiciones cerradas y asumir que, cada dia, las infancias nos muestran 
nuevas aristas de su manera cultural de resignificar el mundo. Desde ahí llegamos a pensar que, precisamente, definirlas desde la estructura de "un niño/a es..." puede suponernos silenciar su resonancia en nuestra acción docente. Es decir, estamos hablando de la constitución un nuevo conocimiento práctico informado que nos invita a dejarnos transformar en nuestra relación con ellos y ellas.

Como tutora, la relación con la documentación pedagógica ha cargado de sentido mi práctica docente en la formación inicial. Desde que la propuse por primera vez en 2010, al hilo de los nuevos aires que Bolonia pretendía inspirar en la universidad, ha permeado cada uno de los procesos que promuevo en mis prácticas cotidianas, no solo en los espacios del practicum. Desde esta experiencia, he podido evidenciar con frecuencia, cómo la documentación pedagógica facilita no solo la comprensión de los procesos educativos donde docentes y discentes comparten vida, emociones, sentido, relaciones y experiencia. Sino también y sobre todo, cómo ha ayudado a los docentes en formación a despertar el deseo de aprender más allá de la mera acumulación de un conjunto de aprendizajes conceptuales aislados del mundo que nos hace latir.

Los tránsitos de aprendizaje propios y las situaciones ajenas, narrados con gran delicadeza por Isabel y Gonzalo muestran la virtualidad pedagógica que la documentación tiene no solo para dignificar y respetar los procesos de crecimiento de la infancia, sino también, para acompañar y estimular los procesos de enseñanza y aprendizaje de los docentes en formación. Un viaje que, sin eludir rutas personales, atraviesa y redibuja el mapa de su identidad docente.

En definitiva, y desde esta experiencia, la documentación pedagógica, puede ayudarnos a construir ese tercer espacio mencionado por Zeichner (2010). Un espacio complejo y complementario de vivencias y reflexión sistemática y tutorizada sobre la práctica singular de cada estudiante. Un espacio que dé cabida al extrañamiento y el asombro de sus propias creencias, a la proxémica como forma de entender la relación educativa, la reflexión e interpretación constante de lo que (nos) acontece y el enseñar como un proceso de acogida y reconocimiento. En definitiva, un contexto que les ayude a identificar, formular y reformular su conocimiento práctico convencional a través del movimiento dialectico y complementario de teorizar la práctica y experimentar la teoría. (Pérez Gómez, 2019)

Como se habrá podido deducir, no sólo es la propuesta pedagógica en sí lo que nos ha brindado una enorme oportunidad para crecer y vivir de una forma que no suele ser común la formación inicial, sino que vivir la experiencia de escribir en común desde lugares diferentes ha supuesto que volvamos a poner la luz en situaciones que quizá, en su momento, no supimos entrar a comprender con tanta profundidad.

Así, lo que hemos querido traer hasta este lugar es sólo un ejemplo de una 
experiencia pedagógica en formación inicial que nos ha resultado relevante, sin pretensión de que ésta sea universalizada. De hecho, retomando por última vez la metáfora de la música como espacio para pensar sobre los procesos educativos, nuestra vivencia con la documentación pedagógica nos ayuda a pensar en una educación que está marcada por su relación con las infancias y que, rescatando unos versos de Rozalén \& Romero (2018), deriva en un terremoto que no nos deja indiferentes:

Un escalofrío de la cabeza a los pies

Yo, más yo que nunca

Ni ahora, ni antes ni después

Un pellizco agudo atravesándome la piel

La más tierna caricia

\section{Referencias}

Altimir, D. (2010). ¿Cómo escuchar a la infancia? Barcelona: OctaedroRosa Sensat.

Aguado Romo, R. (2015). Es emocionante saber emocionarse. Madrid: Editorial EOS.

Argyris, C. (1982). Reasoning, Learning, and Action. Individual and Organizational. San Francisco: Jossey-Bass.

Argyris, C. (1993). Knowledge for Action. A Guide to Overcoming Barriers to Organizational Change. San Francisco: Jossey-Bass Publishers.

Bruner, J. (1997). La educación, puerta de la cultura. Madrid: Visor.

Cabanellas, I. (2005). Territorios de investigación. En I. Cabanellas \& C. Eslava (Eds.), Territorios de la infancia. Diálogos entre arquitectura y pedagogía (p. 181-196). Barcelona: Graó.

Caparrós, E. \& Sierra, E. (2019). Encender el deseo de saber. Movilizar las visiones epistemológicas en la formación inicial de maestras y maestros. Revista Interuniversitaria de Formación del Profesorado, 94 (33,3), 175-194. Disponible en: https://recyt.fecyt.es/index.php/RIFOP/article/view/75746/0

Contreras, J. (2010). Pedagogías de la experiencia y experiencia de la pedagogia. En J. Contreras \& N. Pérez de Lara (Comps.), Investigar la experiencia educativa (p. 241-269). Madrid: Ediciones Morata.

Curtis, D., \& Carter, M. (2012). The art of awareness. How observations can transform your teaching. St. Paul (Minnesota): Readleaf Press.

Dahlberg, G., Moss, P., \& Pence, A. (2005). Más allá de la calidad en educación infantil. Barcelona: Graó.

Dahlberg, G., \& Moss, P. (2010). Ethics and Politics in Early Childhood Education. Londres: Routledge. 
Davoli, M. (2011). Documentar procesos, recoger señales. En Red Territorial de Educación Infantil de Cataluña (Ed.), Documentar la vida de los niños y las niñas en la escuela (p. 15-26). Barcelona: Octaedro-Rosa Sensat.

Greeno, J. G., Collins, A. M., \& Resnick, L. B. (1996). Cognition and learning. En D. C. Berliner \& R. C. Calfee (Eds.), Handbook of educational psychology (p. 15-46). Nueva York: Macmillan.

Darling-Hammond, L. y Oakes, M. (2019). Preparing Teachers for Deeper Learning. Boston: Harvard Education Press.

Hagger, H. \& Hazel, H. (2006). Seeing through teachers' eyes: Professional ideals and classroom practices. Amsterdam: Teachers College Press.

Hoyuelos, A. (2011). Introducción. Educación infantil: Una canción a varias voces. Tarbiya, Revista de Investigación e Innovación Educativa, 42, 5-12. Disponible en:

https://revistas.uam.es/tarbiya/article/view/258

Hoyuelos, A. (2013a). La ética en el pensamiento y obra pedagógica de Loris Malaguzzi. (2a Edición). Barcelona: Octaedro.

Hoyuelos, A. (2013b). La estética en el pensamiento y obra pedagógica de Loris Malaguzzi (2a Edición). Barcelona: Octaedro.

Hoyuelos, A. \& Riera, M. A. (2015). Complejidad y relaciones en educación infantil. Barcelona: Octaedro-Rosa Sensat.

Immordino-Yang, M. H. (2011). Me, My "Self" and You: Neuropsychological Relations between Social Emotion, SelfAwareness, and Morality. Emotion Review, 3(3), 313-315. Disponible en: https://doi.org/10.1177/1754073911402391

Korthagen, F. A. J. (2008). Working with Groups of Student Teachers. En F. A. J. Korthagen (Ed.), Linking practice and theory. The Pedagogy of Realistic Teacher Education (p. 149-174). Nueva York: Routledge.

Korthagen, F. A. J. (2010). La práctica, la teoría y la persona en la formación del profesorado. Revista Interuniversitaria de Formación del Profesorado, 68(24,2), 83-101. Disponible en: https://dialnet.unirioja.es/servlet/articulo?codigo $=3276048$

Lampert, M. (2010). Learning Teaching in, from, and for Practice: What Do We Mean? Journal of Teacher Education, 61(1-2), 21-34. Disponible en: https://doi.org/10.1177/0022487109347321

Lucas, B., \& Claxton, G. (2013). Nuevas inteligencias, nuevos aprendizajes. Inteligencia compuesta, expandible, práctica, intuitiva, distributiva, social, estratégica, ética. Madrid: Narcea.

Malaguzzi, L. (1993). La educación infantil en Reggio Emilia. Barcelona: Octaedro.

Mannay, D. (2017). Métodos visuales, narrativos y creativos en investigación cualitativa. Madrid: Ministerio de Educación, Cultura y Deporte; y Narcea. 
Morin, E. (2001). La mente bien ordenada (2.a ed.). Barcelona: Seix Barral, S. A.

Paz, O. (1990). La otra vez. Poesía y fin de siglo. Barcelona: Seix Barral.

Pérez Gómez, Á. I. (2010). Nuevas exigencias y escenarios para la profesión docente en la era de la información y de la incertidumbre. Revista Interuniversitaria de Formación del Profesorado, 68(24,2), 17-36. Disponible en:

https://core.ac.uk/download/pdf/41577209.pdf

Pérez Gómez, A. I. (2012). Educarse en la era digital. Madrid: Morata.

Pérez Gómez, Á. I., Soto Gómez, E., \& Serván Núñez, M. J. (2015). Lesson Studies: re-pensar y re-crear el conocimiento práctico en cooperación. Revista Interuniversitaria de Formación del Profesorado, 29(3), 81-101. Disponible en:

https://www.redalyc.org/articulo.oa?id=274/27443871006

Pérez Gómez, Á. I. (2017). Pedagogías para tiempos de perplejidad. De la información a la sabiduría. Rosario (Argentina): Homo Sapiens Ediciones.

Pérez Gómez, Á. I. (2019). Ser docente en tiempos de incertidumbre y perplejidad. Márgenes, Revista de Educación de la Universidad de Málaga, O(0), 3-17. Disponible en: http://dx.doi.org/10.24310/mgnmar.v0i0.6497

Pozo, J. I. (2014). Psicología del Aprendizaje Humano. Adquisición de conocimiento y cambio personal. Madrid: Morata.

Red Territorial de Educación Infantil de Cataluña (2012). Documentar, una mirada nueva. Barcelona: Octaedro-Rosa Sensat.

Rinaldi, C. (1998). Projected Curriculum Constructed Through Documentation - Progettazione. An interview with Lella Gandini. En C. Edwards, L. Gandini \& G. Forman (Eds.), The hundred languages of Children. The Reggio Emilia Approach - Advanced Reflections (p. 113-125). Londres: Ablex Publishing Corporation.

Rozalén, M., \& Romero, A. (2018). Al Cantar. En Cerrando Puntos Suspensivos [CD]. Madrid: Sony Music Entertainment España, S.L.

Sparrman, A., \& Lindgren, A. L. (2010). Visual documentation as a normalizing practice: A new discourse of visibility in preschool. Surveillance \& Society, 3(4), 248-261. Disponible en: https://ojs.library.queensu.ca/index.php/surveillance-andsociety/article/view/4154

Schön, D. A. (1992). La formación de profesionales reflexivos. Hacia un nuevo diseño de la enseñanza y el aprendizaje en las profesiones. Madrid: Paidós Ibérica.

Schön, D. A. (1998). El profesional reflexivo. Cómo piensan los profesionales cuando actúan. Madrid: Paidós Ibérica.

Soto Gómez, E., Serván Nuñez, M. J., Trapero, N. P., \& Pérez Gómez, Á. 
I. (2019). Nuevos retos en la formación del profesorado. Lesson Study: acompañar la enseñanza y la investigación. Márgenes, Revista de Educación de la Universidad de Málaga, 0(0), 38-57. Disponible en: https://doi.org/10.24310/mgnmar.v0i0.6504

Tardif, M. (2004). Los saberes del docente y su desarrollo profesional. Madrid: Narcea.

Van Manen, M. (1995). On the epistemology of reflective practice. Teachers and Teaching: Theory and Practice, 1, 33-50. Disponible en: https://doi.org/10.1080/1354060950010104

Van Manen, M. (1998). El tacto en la enseñanza. El significado de la sensibilidad pedagógica. Barcelona: Paidós.

Vilanova Buendía, A. M. (2014). Descender desde la infancia: El desarrollo y el discurso de los "niños" ante "formas otras" de conocer y vivir. Barcelona: Universidad de Barcelona, Doctorado en Educación y Sociedad. Disponible en: http://hdl.handle.net/10803/288209

Wien, C. A., Guyevskey, V., \& Berdoussis, N. (2011). Learning to Document in Reggio-inspired Education. Early Childhood Research and Practice, 13(2). Disponible en: https://ecrp.illinois.edu/v13n2/wien.html

Wylie, S., \& Fenning, K. (2012). Observing Young Children: Transforming Early Learning Through Reflective Practice. Toronto: Nelson College Indigenous.

Zambrano, M. (1989). Notas de un método. Madrid: Mondadori.

Zeichner, K. M. (2010). La formación del profesorado y la lucha por la justicia social. Madrid: Morata. 